\title{
Clinical and symptomatological reflections: the fascial system
}

This article was published in the following Dove Press journal:

Journal of Multidisciplinary Healthcare

18 September 2014

Number of times this article has been viewed

\author{
Bruno Bordoni ${ }^{1,2}$ \\ Emiliano Zanier ${ }^{2,3}$ \\ 'Department of Cardiology, \\ IRCCS S Maria Nascente, \\ Don Carlo Gnocchi Foundation, \\ Milan, Italy; ${ }^{2}$ CRESO Osteopathic \\ Centre for Research and Studies, \\ ${ }^{3}$ EdiAcademy, Milan, Italy
}

Correspondence: Bruno Bordoni; Emiliano Zanier

Email bordonibruno@hotmail.com; fisioheal@yahoo.it

\begin{abstract}
Every body structure is wrapped in connective tissue, or fascia, creating a structural continuity that gives form and function to every tissue and organ. Currently, there is still little information on the functions and interactions between the fascial continuum and the body system; unfortunately, in medical literature there are few texts explaining how fascial stasis or altered movement of the various connective layers can generate a clinical problem. Certainly, the fascia plays a significant role in conveying mechanical tension, in order to control an inflammatory environment. The fascial continuum is essential for transmitting muscle force, for correct motor coordination, and for preserving the organs in their site; the fascia is a vital instrument that enables the individual to communicate and live independently. This article considers what the literature offers on symptoms related to the fascial system, trying to connect the existing information on the continuity of the connective tissue and symptoms that are not always clearly defined. In our opinion, knowing and understanding this complex system of fascial layers is essential for the clinician and other health practitioners in finding the best treatment strategy for the patient.
\end{abstract}

Keywords: fascia, osteopathic, low back pain, neck, pain

\section{Introduction: definition of fascia}

Every body structure is wrapped in connective tissue, or fascia, creating a structural continuity that gives form and function to every tissue and organ. ${ }^{1-6}$ The human body must be considered as a functional unit, where every area is in communication with another through the fascial continuum, consequently originating perfect tensegritive equilibrium. ${ }^{5}$ Medical literature does not suggest a sole definition of fascia, because it varies in terms of thickness, function, composition, and direction depending on its location. The fascial tissue is equally distributed throughout the entire body, enveloping, interacting with, and permeating blood vessels, nerves, viscera, meninges, bones, and muscles, creating various layers at different depths, and forming a tridimensional metabolic and mechanical matrix. ${ }^{6,7}$ The fascia becomes an organ that can affect an individual's health. ${ }^{8}$ Awareness of its functions and of the areas it controls becomes significant within a more general perspective concerning the patient's wellness and health (Figure 1).

From an embryological perspective, the fascial system originates in the mesoderm, although according to some authors this connective network can be partially found in the neural crests (ectoderm), with particular reference to the cranial and cervical area. $^{8-10}$

The most external layer is denominated subcutaneous fascia or loose (areolar) connective fascia. ${ }^{7,11}$ This layer is made up of several levels, each with variable 

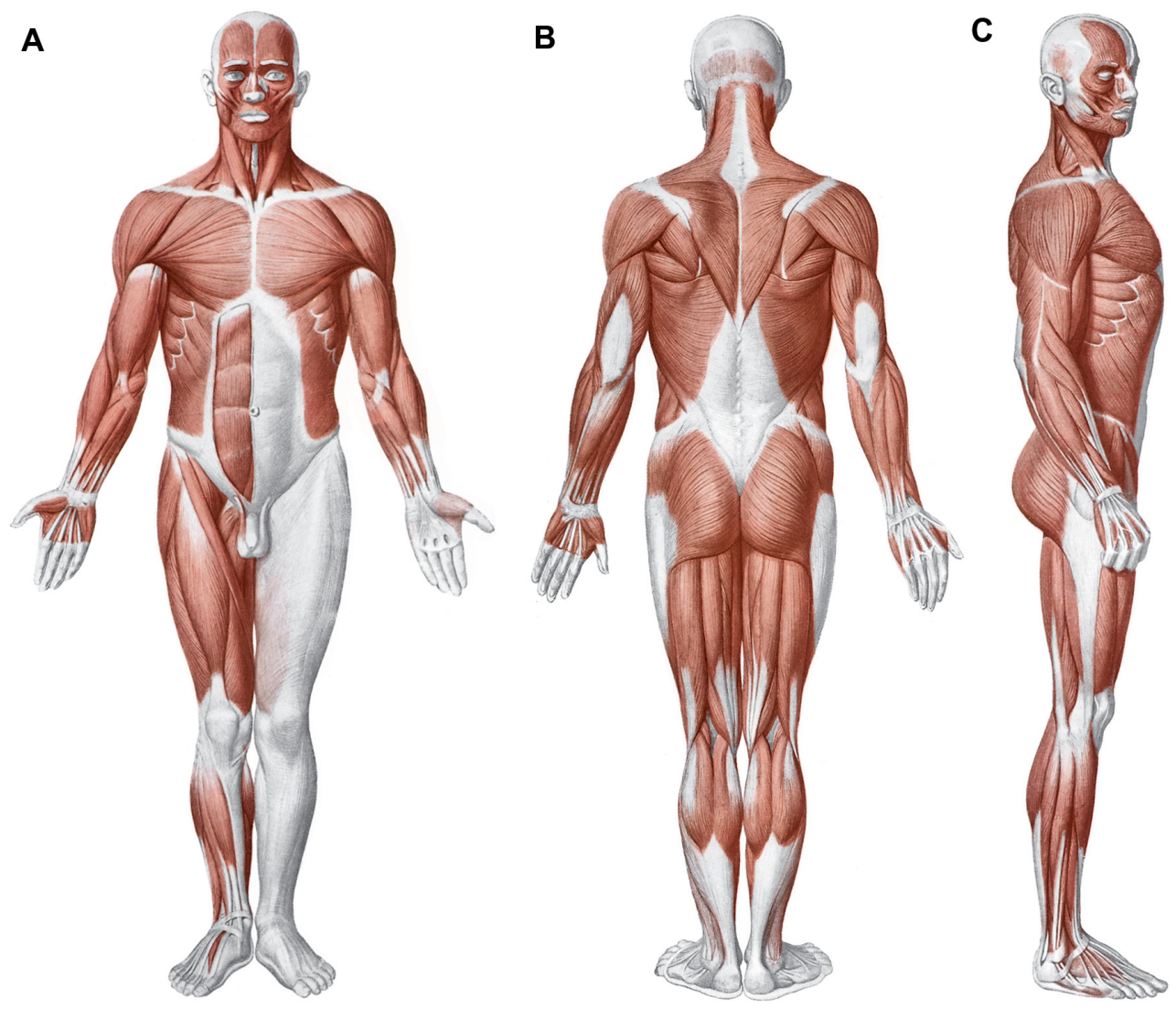

Figure I Shape and arrangement of the muscles on the ventral (A), dorsal (B), and lateral (C) surface of the human body.

Notes: Copyright Edi.Ermes, Milano. Reproduced with permission from Anastasi et al. AA VV, Anatomia dell'uomo, 4th ed, Edi.Ermes, Milano [Human anatomy]. ${ }^{13}$

amounts of fibroblasts (ie, connective cells) arranged in a disorderly manner and soaked in a gelatinous substance known as extracellular matrix, where numerous molecules (ie, glycosaminoglycans, proteoglycans and polysaccharides such as hyaluronic acid) can be found. ${ }^{3,12}$ This superficial layer is not located exclusively under the derma, but it permeates the entire body, enveloping the organs and forming the stroma, the neurovascular branches, and the different fascias of the muscle districts, finally resting on the deep fascia. ${ }^{13-15}$ The superficial fascia is made up of different layers, whose formation facilitates the sliding of one layer over another, as of the structures enveloped or in contact with the aforesaid fascia. ${ }^{12-15}$ The number of layers of the superficial fascia and the amount of substances they contain depend on the quantity of fat, the sex, and the body area concerned. ${ }^{12,13}$ The superficial fascia is rich in water, arranged in liquid crystals. ${ }^{16}$ The various layers communicate by a microvacuolar system, which is in turn composed of the same structures of the superficial fascia; it is a microscopic web, concerning vessels and nerves, in varying directions, and is highly deformable. ${ }^{11}$ According to some texts, within the superficial fascia there is a vascular network independent of the lymphatic and blood pathways. It is called the Bonghan duct system, and supposedly eases communication among all body areas. ${ }^{17-21}$ This system is composed of the same substance forming the superficial fascia. ${ }^{9}$

The deep fascia is the last connective layer before coming in contact with the somatic structure (ie, bones and muscles), and the visceral and vascular systems. It is characterized by various levels of loose connective tissue., ${ }^{3,22}$ Its vascular and lymphatic system is well developed, with numerous corpuscles in charge of proprioception, particularly the Ruffini's and Pacini's corpuscles..$^{22}$ It is a less extendable fibrous layer, with collagen fibers arranged more regularly, thick and parallel to each other; it is rich in hyaluronic acid., ${ }^{722}$

According to some authors, the fascial layer enveloping the organs is a serous fascia, but in fact it is the prolongation of the deep fascia. ${ }^{1,23}$

All fascial layers contain a variable amount of fibroblasts with the ability to contract, known as myofibroblasts. They contain a type of actin similar to the one traceable in the muscles of the digestive system; ie, alpha-smooth muscle actin. ${ }^{6}$ Scientific research has proven that the fascial continuum is innervated by the autonomic sympathetic system. ${ }^{6}$ 


\section{Symptoms: facts and hypotheses}

The fascial continuum is essential for transmitting the muscle force, for correct motor coordination, and for preserving the organs in their sites: the fascia is a vital instrument that enables the individual to communicate and live independently. The transmission of the force is ensured by the fascial integrity, which is expressed by the motor activity produced; the tension produced by the sarcomeres results in muscle activity, using the various layers of the contractile districts (epimysium, perimysium, endomysium), with different directions and speed (Figure 2). ${ }^{6,11,24,25}$

The connective tissue can control the orientation of the muscle fibers, so as to reflect the vector of the force's direction, and to render the transition of the tension more fluid and ergonomic. ${ }^{24}$ The fascial system is rich in proprioceptors, particularly the Ruffini's and the Pacini's corpuscles, mostly in the areas of transition between the articulation and the fascia, and between the fascia and the muscular tissue, blending with the receptors of these structures. ${ }^{6.8}$ The fascial continuum can be considered a sense organ of human mechanics, which affects daily postural patterns. ${ }^{6,8,26}$

The muscle system is part of the fascial continuum, and when it is affected by pathologies or systemic disorders such as visceral, genetic, vascular, metabolic and alimentary disorders, its function undergoes a nonphysiological alteration; there are many epigenetic processes that can lead to its adjustment as a response to mechanotransductive stimuli, resulting in further decrease of its function and properties. ${ }^{27-37}$ Once

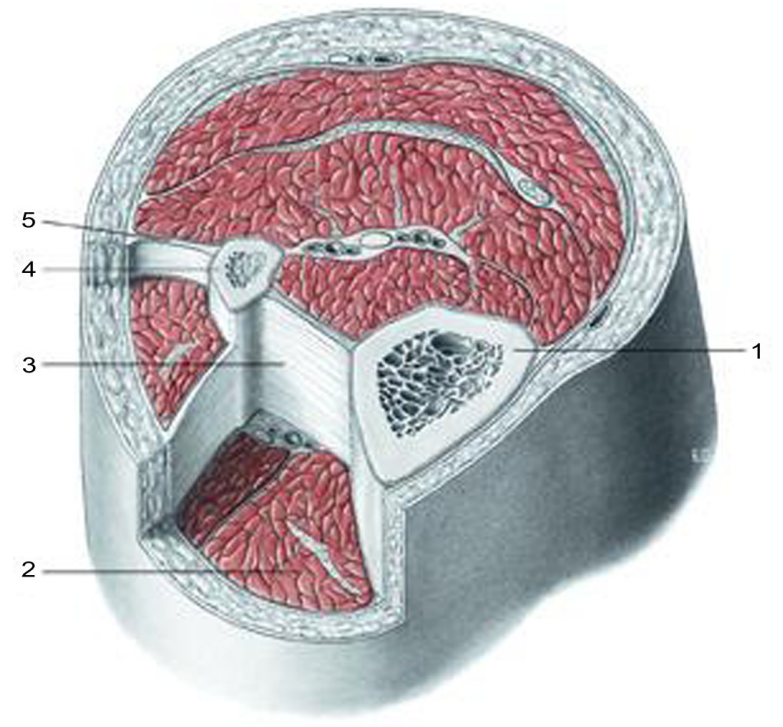

Figure 2 Transverse section at the level of the upper third of the leg. Notes: I, tibia; 2, muscular loggia; 3 , interosseous membrane; 4, fibula; 5 , intermuscular septum. All tissues are enveloped by fascial continuum. Copyright Edi.Ermes, Milano. Reproduced with permission from Anastasi et al. AA VV, Anatomia dell'uomo, 4th ed, Edi.Ermes, Milano [Human anatomy]. ${ }^{113}$ altered, the fascial continuum generates a symptomatology that deteriorates the health condition of the patient, very often developing symptoms that are more significant than the clinical parameters diagnosed through medical diagnostic devices. ${ }^{38-41}$ Chronic fatigue, for instance, can be associated with the fascial system, particularly when the pathological disorder has persisted for several years ${ }^{42}$ Recent experimental studies have shown that common physiological mechanisms may be involved in the causation of muscle pain and fatigue; the nociceptive afferent inputs from the fascial system can modulate the afferent response from the central nervous system. ${ }^{42}$ If the afferent is not physiological, the efferent will be in dysfunction and in pathology. ${ }^{42}$

An increased level of circulating cytokines originating in the connective system, due to systemic pathologies, could develop neuropathic pain. ${ }^{43-46}$ The connective tissue can directly convey pain signals; in fact, it contains nociceptors that can translate mechanical stimuli into pain information. Furthermore, if there are nonphysiological mechanical stimuli, the proprioceptors can turn into nociceptors. ${ }^{3,6,7}$ There are many reasons why the fascial continuum can turn into a source of pain. The nociceptors synthesize some neuropeptides that can alter the surrounding tissue, and generate an inflammatory environment; the epineurium and the perineurium, both belonging to the fascial system, are innervated by the nervi nervorum, which can develop pain sensation creating a vicious circle, when they are in contact with pro-inflammatory molecules. ${ }^{6,47}$ All the fascial layers need hyaluronic acid to slide over each other; if its quantity decreases or it is not regularly distributed, the local or systemic sliding property of the connective tissue is compromised. ${ }^{12}$ There are some researchers who suggest strongly that any change in the viscoelasticity of the fascial system activates the nociceptors. ${ }^{3,12}$ The hyaluronic acid becomes adhesive and less lubricated, altering the lines of forces within the various fascial layers. ${ }^{3}$ This mechanism could be one of the causes of articular stiffness and pain in the morning. ${ }^{11}$ In fact, the stiffness experienced by some patients when they wake up in the morning could be related not with the joint but with the fascial system: if there is a minor quantity of hyaluronic acid or when it is not equally distributed, the tissue is dehydrated and has less possibility of sliding., ${ }^{3,11,12}$ The same dehydration prevents the catabolites of cellular metabolism from being properly removed, stimulating the nociceptors; the accumulation of metabolites alters the $\mathrm{pH}$ inside the fascia, making a more acid cell environment; this results in dysfunctional physiology of the hyaluronic acid, and complicates the sliding of the different fascial layers, again stimulating the nociceptors. ${ }^{3,12}$ 
Reduced sliding of the various layers limits the functionality of the endocannabinoid system. There is a close relationship between the endocannabinoid or endorphin system and the fibroblasts. The cannabinoid receptor, or CB1, is mainly housed in the nervous system, but it can be found in the fascial system and in the fibroblasts as well, particularly near the neuromuscular junction. ${ }^{48}$ This relationship is believed to better manage any inflammation and pain information originating in the fascial tissue, as the fascia undergoes continuous remodeling during the day. ${ }^{48,49}$

It is hypothesized that the axoplasmic flow originating in the dorsal ganglionic roots carries some molecules to the distal nerve endings, in an attempt to reduce pain information deriving from the nociceptors in the fascial continuum; if there is a mechanical barrier owing to a reduction of the fascial sliding, the axoplasmic flow will be hindered, with consequent onset of hyperalgia. ${ }^{48}$ The nerve has the ability to adjust itself in case of length variations of the extremities and trunk, in order to preserve its functions; in case of difficulty in sliding of the different layers that are crossed by the nerve structure, there is a neural tension or neurodynamic dysfunction, developing sensations of pain. ${ }^{3,50}$ This is due to a reduction in the intraneural blood flow, and to the release of inflammatory neuropeptides..$^{50}$ According to some authors, the loss of a correct sliding of the layers is demonstrated by an increased density of the fascial thickness, which can be detected through ultrasonography, explaining atypical symptomatology of chronic pain; this phenomenon is not termed fibrosis but fascial densification. ${ }^{3,51}$

Defective sliding, for instance due to a scar, generates anomalous tension, which then affects the fascial continuum, developing painful symptoms. ${ }^{1,52}$ Tensional alterations can derive from the contractile property of fibroblasts, creating a fascial tonus that is independent of neurological intervention. ${ }^{1,52,53}$ A nonphysiological mechanical environment stimulates an inflammatory environment, with resultant fibroblasts' hyperplasia and further fascial densification, which then develops into chronic inflammation and into the sensitization of nociceptors. . $^{10,47,54,55}$ The inflammation experienced by fibroblasts increases the extracellular edema; this edema depends not only on an increased vascular permeability, but also on loose fascial tissue, which draws liquids inside..$^{52}$ The edema determines an increase in tension and stiffness, resulting in difficult sliding of the fascial layers and pain. ${ }^{52}$ This scenario makes the fibroblast release adenosine triphosphate (ATP), stimulating the nociceptors. ${ }^{52,55}$ It is probable that the alteration of the physiological flow of fluids such as lymph and blood, caused by a tensional anomaly experienced by fibroblasts, is related to one of the causes of local and systemic pathologies, such as the formation of tumors. ${ }^{52}$ The sensitization of nociceptors could derive from a local ischemia, caused by nonphysiological fascial tension, which hinders the skeletal muscle from functioning properly, for instance in trigger points. ${ }^{56,57}$ Pain receptors could be activated by inflammatory molecules, ATP and glutamate (an important neurostimulator), a decrease in $\mathrm{pH}$, and other neuropeptides (such as substance $\mathrm{P}$ and calcitonin gene-related peptide). ${ }^{56}$ These alterations, which are mostly considered muscular alterations, can also be determined by visceral effects on the muscle tissues, proving the continuity of the fascial system..$^{57-59}$

The fibroblasts (the foundations of the fascial system) affect the immune system, and as a consequence bone tissue; this phenomenon is called osteoimmunology. ${ }^{47,60}$ The immune system and bone tissue share molecular interactions, including transcription factors, signal molecules and membrane receptors; in particular, osteoclasts are sensitized by cytokines, and vice versa. ${ }^{61}$ When the layers of the fascial continuum do not slide properly over one another, from the most superficial layer to the periosteum, an inflammatory environment develops, either acute or chronic; the resultant cytokines could activate the osteoclasts and bone resorption, generating osteoporosis in the long run. ${ }^{7,61}$ This is probably one of the causes producing articular disorders in rheumatoid arthritis. $^{47}$

Densification can develop into fibrosis. Fibrosis or fibromatosis results from a disorder of the connective tissue affected by hyperplasia and hypertrophy of the fibroblasts, due to a chronic inflammatory environment, nonphysiological mechanical stress and immobility; calcification phenomena can be observable as well. ${ }^{47}$ These morphological and functional variations have been verified in elbow tendonitis and in plantar fasciitis. ${ }^{47}$ The fibroblasts lose their physiological direction, which is determined by new pathological force vectors, revealing a chaotic organization. ${ }^{47,62} \mathrm{In}$ the presence of a fibromatosis similar to the cicatricial tissue, for instance in Dupuytren's contracture, there is an increase in the percentage of fibroblasts, which then change into myofibroblasts, with consequent altered tension experienced by the fascial continuum; the result is a vicious circle of inflammation and activation of the nociceptors. ${ }^{62}$ The important event that must be underlined is that the connective tissue found next to an ailing fascial area undergoes nonphysiological mechanical stimuli, resulting in further functional deterioration of the fascial layers. ${ }^{62}$ This mechanism, which alters the correct distribution of the tension generated and perceived, concerns 
the entire fascial continuum, and all the structures it surrounds and sustains. ${ }^{63-65}$

\section{Clinical scenarios: facts and hypotheses}

Research has proven that patients who suffer from chronic lumbar backache present an inflammation of the local fascial area, and experience degenerating variations of collagen fibers and microcalcifications, besides a $25 \%$ increase in thickening of the perimuscular fascial tissue if compared with nonsuffering subjects. ${ }^{47}$ The entire thoracolumbar fascia plays a fundamental role in this pathological condition. ${ }^{66}$ The absence of sliding of the different layers in the lumbar area and the morphological alteration of the tissue generate a nonphysiological mechanical tension, resulting in lumbar pain symptoms. ${ }^{66}$ This nonphysiological condition develops a lack of coordination in the activation of the muscles of the thoracolumbar fascia involved, with resultant mechanical instability of the lumbar column and pain. ${ }^{67}$ Pain symptoms are intensified by stress, as the fascia is innervated by the sympathetic nervous system, especially in the area near the blood vessels; therefore, it is likely to produce vasospasm and ischemic pain. ${ }^{47,68}$ This negatively affects posture and walking. ${ }^{6,66}$ From the current data in the literature, we can strongly assume that the connective tissue is more responsive than the muscular tissue in the activation of nociceptors, and examination on animals has proven that the medullar neurons receiving fascial nociceptive afferents are activated $4 \%$ to $15 \%$ more than a noninflamed fascia, with an experimentally-induced inflammation of a low back pain muscle (multifidus). ${ }^{68-70}$ The thoracolumbar fascia proceeds with the gluteus maximus and the lower extremity, involving the fascia of the thigh, the leg, and the plantar fascia of the foot, and is closely related to the pelvic floor. ${ }^{65,71-77}$ We can logically hypothesize a problem of instability in the ankle caused by the anatomical connection with the thoracolumbar fascia, because of a proprioceptive alteration of the fascial continuum and of its relevant muscular coordination. An aching ankle has been proven to cause urogenital and visceral disorders, such as dyspareunia. ${ }^{64}$ This event can be explained by the muscular connections existing between the pelvic floor and the ankle (rectum abdominis, adductor lungus and triceps surae), producing hypertonus of the pelvic musculature, and by nociceptive information, which at the medullar level can develop a metabolic and electrical antidromic communication, and involve a greater number of neurons of the metameric segment, consequently concerning the viscera (somaticovisceral reflex). ${ }^{64,65,78}$ The fascial continuum can also develop symptoms in areas which are far from the original dysfunctional point, making it more difficult to diagnose the patient's clinical scenario. For this reason, a patient must be observed as a sole entity and not as a collection of single body segments. ${ }^{1,65}$

In atypical cervicalgia an alteration in the thickness of the fascial layers has been verified, with consequent altered spinal mobility and pain. ${ }^{3,51,79}$ This reduction of movement of the layers is called fascial stasis, because in this state the fascial fluids flow with difficulty. The cervical tract has a fundamental importance for correct occlusion and postural balance; its dysfunction alters mastication and balance. ${ }^{80-83}$ The muscles involved in mastication, with opening and closing of the jaw, are surrounded by the cervical fascia: suprahyoid, masseteric, pterygoid, lingual and temporal muscles. ${ }^{84,85}$ We can reasonably assert that a dental disorder can directly originate in the thickening of the cervical fascial layers; in this event, a therapy merely aimed at restoring the functionality of the occlusion will be ineffective, if the cervical area is not treated.

Cervical fascia and visual control are closely related. There is a variety of reflexes, such as the vestibulo-ocular reflex (ie, the eyes move as a result of vestibular information), the optokinetic reflex (they move in response to the stimulation of visual movement), and the cervico-ocular reflex, occurring when the head is turned, in order to stabilize the image on the retina while the head is moving. ${ }^{86,87}$ Any dysfunction in the cervical fascial area will be problematic for these reflexes. ${ }^{86,87}$ This is due to the lack of coordination of the muscular areas belonging to the cervical fascial layers, and the connection with the cranial fascia. ${ }^{87}$ The posterior superficial cervical fascia (the continuation of the thoracolumbar fascia), which surrounds the nuchal line, merges with the superior lateral two-thirds of the occipitofrontalis muscle. ${ }^{65,88}$ The occipitofrontalis muscle runs from the condylar area of the occiput under the superficial cranial fascia, and then through an ample aponeurosis called Galea aponeurotica comes in contact with the frontal venter musculi, bridging the gap between the occipital bone and the frontal one. ${ }^{88}$ The superficial fascia of the skull concerns the temporoparietal fascia, which then combines with the venter musculi of the frontal portion. ${ }^{88}$ The occipitofrontalis muscle is connected with Muller's muscle; ie, musculus levator palpebrae (Figure 3). ${ }^{88}$

The connective tissue of Muller's muscle is rich in mechanoreceptors, so as to induce a reflex contraction of the occipitofrontalis muscle, and to keep the eyes aligned for correct posture. ${ }^{89}$ When there is hyperreflexia of the mechanoreceptors in Muller's muscle, the contraction of the occipitofrontalis muscle is hyperstimulated, with resultant 


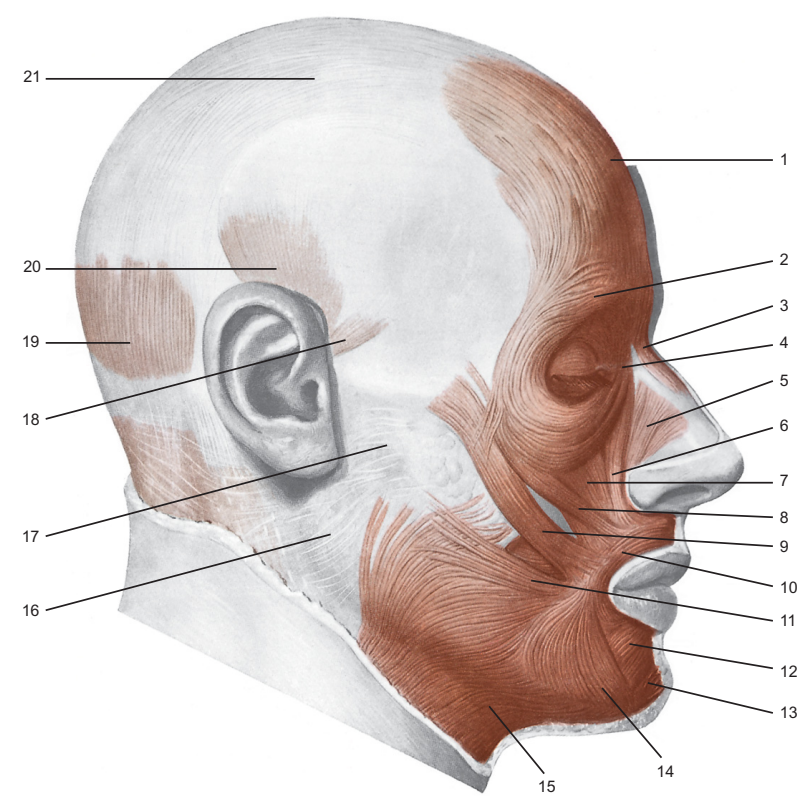

Figure 3 Presentation of the mimic muscles of the head. These muscles occupy a superficial position.

Notes: I, frontal muscle; 2 , orbicularis oculi muscle, part of the eyelid; 3 , procero muscle; 4, medial palpebral ligament; 5, nasal muscle; 6, elevator muscle of the upper lip and of the wing of nose muscle; 7, elevator of the upper lip muscle; 8 , small zygomatic muscle; 9 , great zygomatic muscle; 10 , orbicularis oris muscle; II, risorio muscle; 12, squared muscle of the inferior lip; 13, mentalis muscle; 14, triangular muscle; 15, platysma muscle; 16, parotid fascia; 17, fascia masseter; 18, anterior auricular muscle; 19, occipital muscle; 20, temporoparietal and upper auricular muscles; 2I, aponeurotic galea. Copyright Edi.Ermes, Milano. Reproduced with permission from Anastasi et al. AA VV, Anatomia dell'uomo, 4th ed, Edi.Ermes, Milano [Human anatomy]. ${ }^{113}$

chronic tension in the cervical area and headache. ${ }^{90}$ The more the eyelid is lowered, the greater the extension of the high cervical tract is needed, in order to keep a good visual field, with involuntary involvement of the muscular connective system, generating further hypertonia.$^{88}$ The occipitofrontalis muscle is significant from an ontological perspective as well as for a child's growth, because its tension is fundamental for correct development and regular morphology of the skull, and again it is essential for its influence on the spheno-occipital synchondrosis during the growth, and to facilitate the development of a good phonatory system. ${ }^{91}$ Muller's muscle is connected with Tenon's capsule, where the eyeball is located; particularly, they share extraocular muscles; Tenon's capsule surrounds the optical nerve where it terminates in the eye, blending with the meningeal tissue. ${ }^{92,93} \mathrm{We}$ can theorize that a tension in the fascial area of the high cervical tract will affect the movement of the eyeball, altering the visual field and posture, or causing dysfunction related to the fascial traction on the optical nerve, with resultant alteration in the ocular reflexes. Further studies are needed. The functional and tensional integrity of the fascial continuum plays a major role in the nonpathological homeostasis, and guarantees the patient a satisfactory quality of life in terms of socialization and independence (Figure 4).

The vascular tree is surrounded by the connective system, and its continuity enables the myocardium to affect all the areas permeated by blood with its systole and diastole. ${ }^{7,94}$ The heart itself is surrounded by a tridimensional system of connective tissue, which connects it to the lungs and to the endothoracic fascia (Figure 5). ${ }^{65,95-97}$

The latter is the continuation of the cervical fasciae, which enter the extracranial and intracranial fasciae through the dural leaflets. ${ }^{65}$ The cardiovascular tree embriologically originates in the ectoderm and mesoderm, as does the fascial continuum..$^{8-10,98,99}$ The pathway of the nervous system, whether it is central or peripheral, concerns the fascial continuum. ${ }^{713-15}$ This close connection explains the cerebral motility caused by cardiovascular pulsatility; the cerebral oscillatory activity is synchronized with the systole and diastole of the heart. ${ }^{100}$ This activity concerns the entire spinal axis, and involves a caudal thrust to the cerebellar foramen magnum, during the systole, and a cranial reflex, during the diastole. ${ }^{100}$ The aforementioned cerebral oscillation is perceived by osteopaths through cranial movement. ${ }^{100,101}$ Recent research has proven that human touch can distinguish extremely light objects or slight vibrations. In static palpation, the range of discrimination in case of vibrations reaches $0.2 \mathrm{~mm}$, whereas discrimination while touching a moving surface is measured in microns. ${ }^{102}$ Cerebral oscillations affect the production of cerebrospinal fluid or liquor. ${ }^{100}$ Recent studies have demonstrated that the liquor is mostly

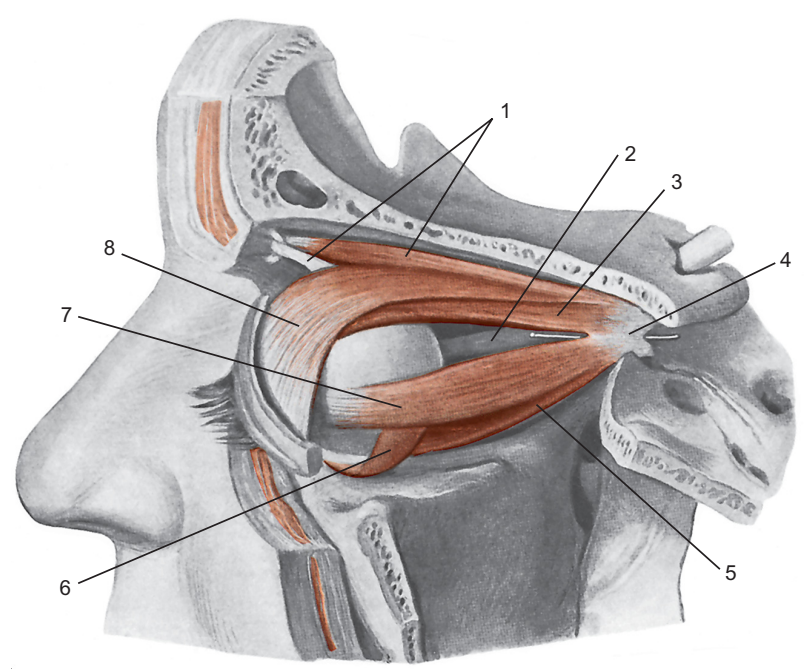

Figure 4 Diagram showing the elevator muscle of the upper eyelid and extrinsic muscle of the eyeball, after lifting the cranial vault and the lateral wall of the orbit. Notes: I, Superior oblique muscle; 2, optic nerve; 3, superior rectus muscle; 4, tendinous ring of Zinn; 5, inferior rectus muscle; 6, inferior oblique muscle; 7, lateral rectus muscle; 8, superioris levator palpebrae muscle. Copyright Edi. Ermes, Milano. Reproduced with permission from Anastasi et al. AA VV, Anatomia dell'uomo, 4th ed, Edi.Ermes, Milano [Human anatomy]. ${ }^{113}$ 


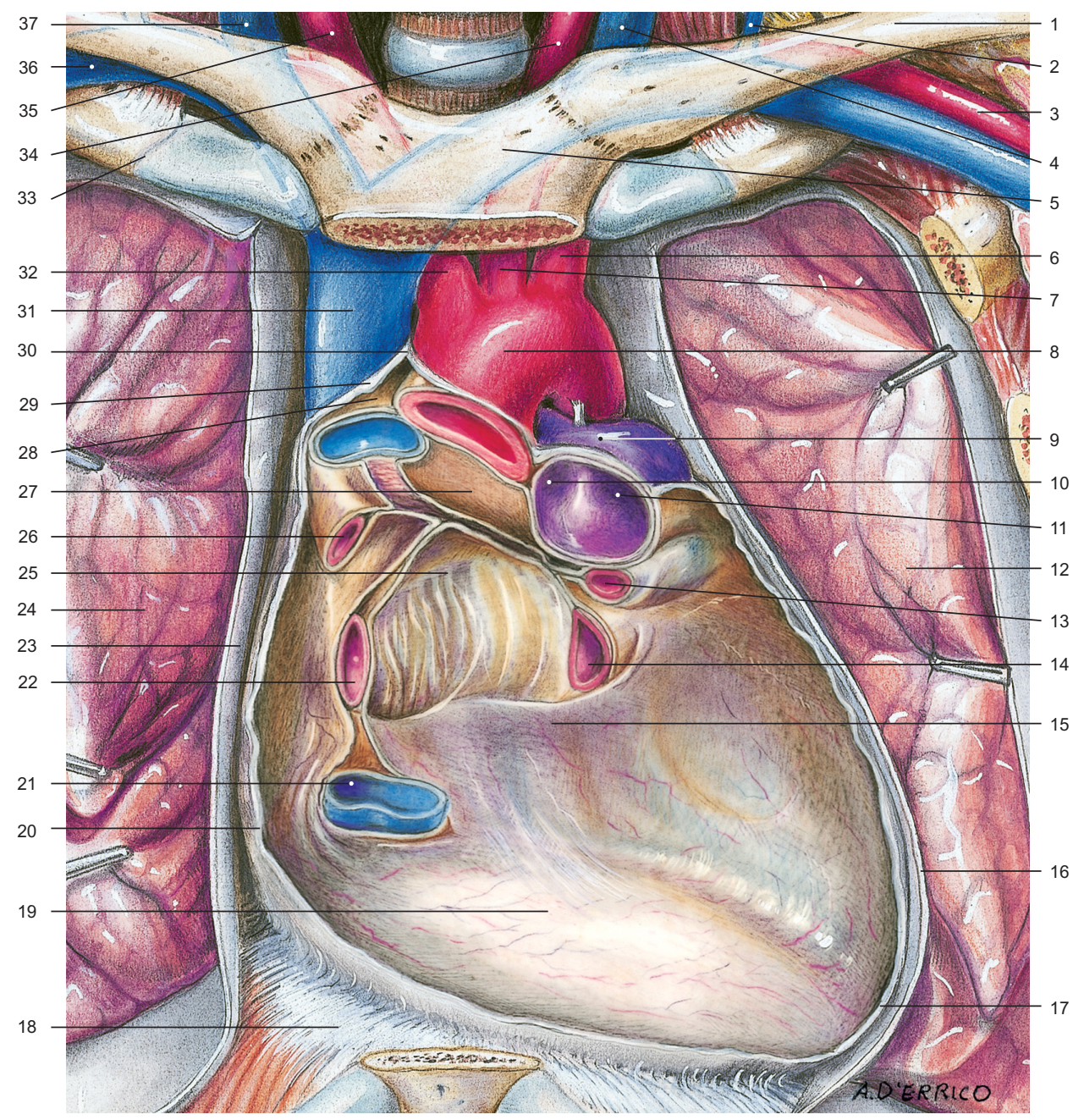

Figure 5 Aspect of the pericardium after resection and removal of its anterior wall, the great vessels, and heart.

Notes: In evidence the base of the heart, the posterior wall and the areas of folding of the serous pericardium at the level of the great vessels. I, left clavicle; 2 , left external jugular vein; 3, left subclavian artery; 4, left internal jugular vein; 5, sternal manubrium; 6, left subclavian artery; 7, left common carotid artery; 8, carotid arch; 9, pulmonary trunk; I0, right pulmonary artery; II, left pulmonary artery; I2, left lung; I3, left upper pulmonary vein; I4, left inferior pulmonary vein; I5, posterior wall; I6, left mediastinal pleura; 17, pericardial sac; 18, diaphragm; 19, base; 20, pericardial sac (dissected); 21, inferior vena cava; 22, right lower pulmonary vein; 23, right mediastinal pleura; 24, right lung; 25, diverticulum Haller; 26, upper right pulmonary vein; 27, transverse sinus of the pericardium; 28, visceral layer; 29 , serous pericardium, parietal layer; 30 , apex of the pericardial sac; 31 , superior vena cava; 32, brachiocephalic trunk; 33, right first rib; 34, left common carotid artery; 35 , right common artery; 36, right subclavian vein; 37, right internal jugular vein. Copyright Edi.Ermes, Milano. Reproduced with permission from Anastasi et al. AA VV, Anatomia dell'uomo, 4th ed, Edi.Ermes, Milano [Human anatomy]. ${ }^{113}$

drained by the lymphatic system, flowing from the perineural and perivascular sheaths to the lymphatic vessels; when it is in the lymphatic system, the liquor flows to the cribriform plate of the ethmoid bone, and then to the epithelium and the nasal mucosa (Figure 6). ${ }^{103,104}$

From here, a system of vessels and lymphatic nodes carry the liquor to the buccal floor and the neck, finally involving the venous system. ${ }^{105-107}$ When the heart suffers from rhythm alteration, patients are treated with drugs to regulate the rhythm and arrhythmia, or they are surgically treated, for instance with ablations, or with temporary/permanent placement of pacemakers and defibrillators (implantable cardiac defibrillators) (Figure 7). ${ }^{108-110}$
We can hypothesize that pharmacological or surgical treatment that regulates cardiac frequency, as well as the pathological alteration of the rhythm, alters the production of the cerebrospinal liquor, and as a consequence negatively affects the environment of nasal mucosa, resulting in rhinitis or sinusitis. An imbalance in the quantity of liquor can alter the immunological environment, whether cerebral or systemic, as it transports many substances (ie, electrolytes, catabolites, hormones and neuropeptides). ${ }^{100,104,107}$ Altered homeostasis of the nasal mucosa and of the olfactory nerve can develop disorders in the superior respiratory tract, which can convey germs to the cerebral area, through the lymphatic pathways departing from the brain. ${ }^{104}$ 


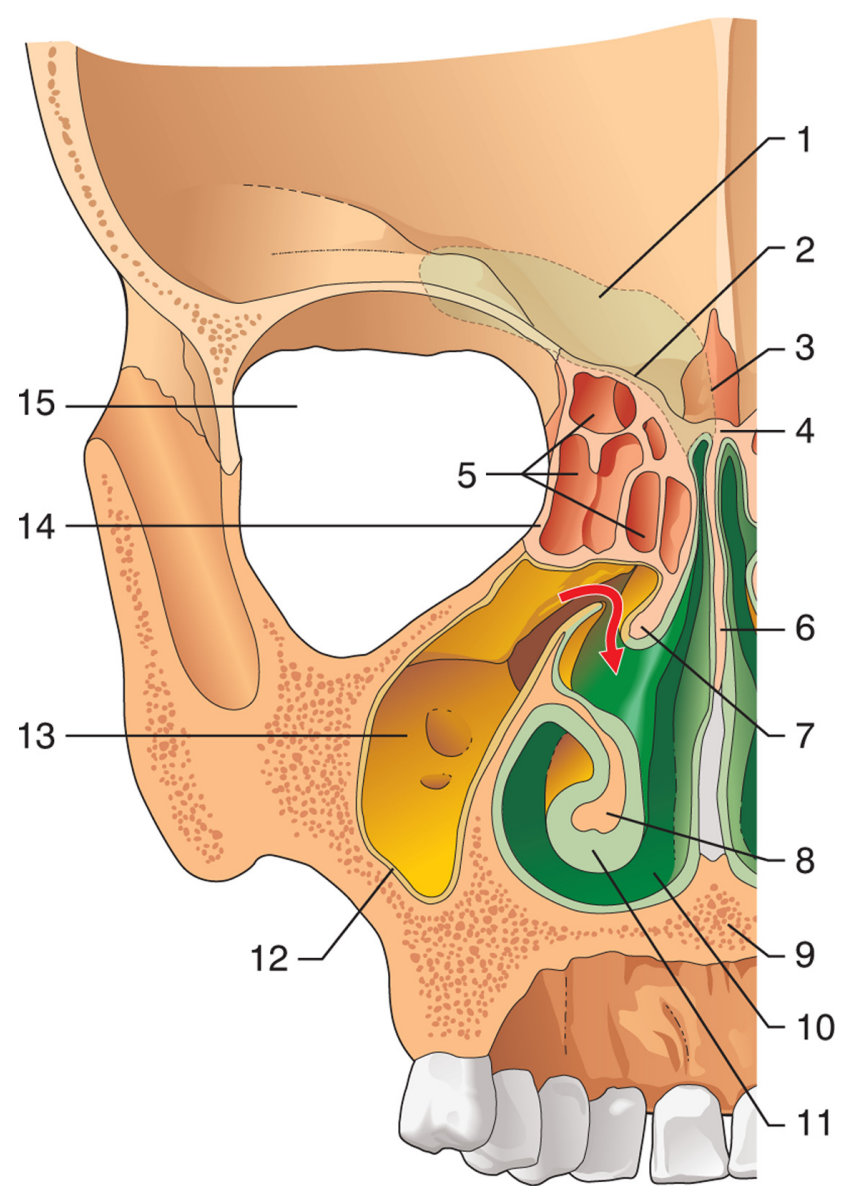

Figure 6 Schematic representation of the front section of the nasal cavity viewed from the rear face.

Notes: The section captures the outlet of the maxillary sinus into the nasal cavity (red arrow). I, frontal sinus; 2, cribriform plate; 3, crista galli; 4, ethmoid bone; 5 , ethmoidal cells; 6 , perpendicular plate; 7 , media nasal concha; 8 , inferior nasal concha; 9, hard palate; 10, nasal cavity; II, mucosa of the nasal cavity; 12, mucosa of the maxillary sinus; 13, maxillary sinus; 14, orbital plate; 15, orbit. Copyright Edi. Ermes, Milano. Reproduced with permission from Anastasi et al. AA VV, Anatomia dell'uomo, 4th ed, Edi.Ermes, Milano [Human anatomy]. ${ }^{113}$

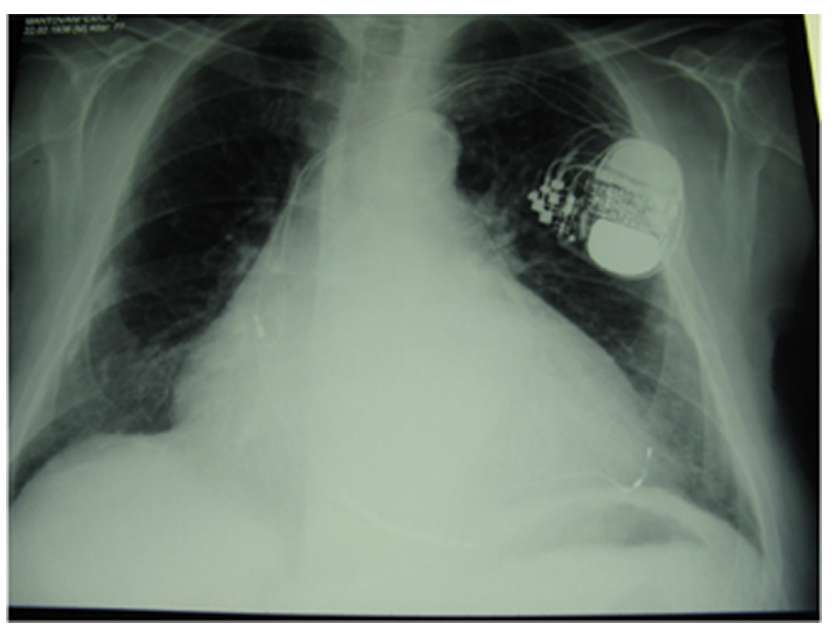

Figure 7 X-ray shows an implantable cardiac defibrillator/pacemaker following heart surgery.

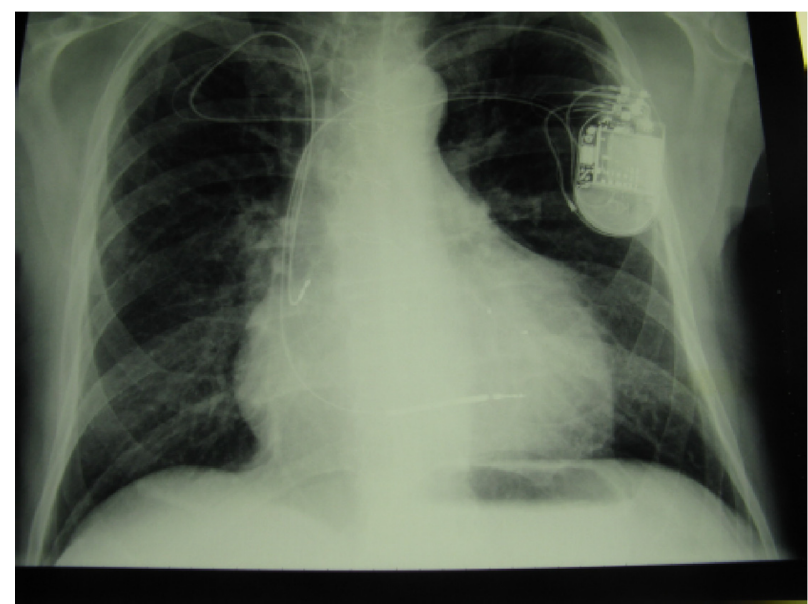

Figure 8 Pacemaker biventricular-bicameral/implantable cardiac defibrillator. Notes: X-ray shows a slight elevation of the left hemidiaphragm due to a lesion of the phrenic nerve following sternotomy after heart surgery.

A lesion in the phrenic or vagal nerve results in dysfunction of the contractile activity of the diaphragmatic muscle. ${ }^{65}$ The respiratory diaphragm and the nerves that electrically activate the muscle belong to the fascial continuum, which merges with the intracranial meningeal tissue, passing through the endothoracic, thoracolumbar and cervical fascia, and involving the viscera in the thoracic cage. ${ }^{65,111,112}$ Respiration, particularly forced respiration, has been proven to affect cerebral motility and the synthesis of cerebrospinal liquor. ${ }^{100}$ Forced expiration generates a caudal movement of the brain, whereas forced inspiration causes the cephalic drainage. ${ }^{100}$ We can theorize that if the diaphragmatic muscle does not have a regular contraction, it negatively affects the production of liquor, endangering one's health (Figure 8).

The same vasomotor activity of blood and lymphatic vessels that is controlled by the autonomous system can affect the synthesis of liquor, although less importantly and independently of the cardiac and respiratory rhythm. ${ }^{100}$ Again, we can assume that a dysfunction of the sympathetic system, resulting from chronic nociceptive information of the fascial continuum (for instance, due to a cicatricial adhesion), alters the synthesis of cerebrospinal liquid, with consequent reduction of systemic homeostasis. ${ }^{1}$

\section{Conclusion}

Currently, there is still little information on the functions and interactions between the fascial continuum and the body system; unfortunately, in medical literature there are few texts explaining how fascial stasis or altered movement of the various connective layers can generate a clinical problem. Certainly, the fascia plays a significant role in conveying 
mechanical tension, in order to control an inflammatory environment. The fascia is the philosophy of the body, meaning that each body region is connected to another, whereas osteopathy is the philosophy of medicine, meaning that the entire human body must work in harmony. Knowing and understanding this complex system of fascial layers is essential for the clinician, and all health practitioners, in finding the best treatment strategy for the patient.

\section{Acknowledgment}

We want to thank Fabiola Marelli, the Director of CRESO, Osteopathic Centre for Research and Studies, for her friendship and support.

\section{Disclosure}

The authors report no conflicts of interest in this work.

\section{References}

1. Bordoni B, Zanier E. Skin, fascias, and scars: symptoms and systemic connections. J Multidiscip Healthc. 2013;7:11-24.

2. Abbott RD, Koptiuch C, Iatridis JC, Howe AK, Badger GJ, Langevin HM. Stress and matrix-responsive cytoskeletal remodeling in fibroblasts. J Cell Physiol. 2013;228(1):50-57.

3. Stecco A, Gesi M, Stecco C, Stern R. Fascial components of the myofascial pain syndrome. Curr Pain Headache Rep. 2013;17(8):352.

4. Buckley CD. Why does chronic inflammation persist: An unexpected role for fibroblasts. Immunol Lett. 2011;138(1):12-14.

5. Bordoni B, Zanier E. Cranial nerves XIII and XIV: nerves in the shadows. J Multidiscip Healthc. 2013;6:87-91.

6. Tozzi P. Selected fascial aspects of osteopathic practice. J Bodyw Mov Ther. 2012;16(4):503-519.

7. Findley TW, Shalwala M. Fascia Research Congress evidence from the 100 year perspective of Andrew Taylor Still. J Bodyw Mov Ther. 2013;17(3):356-364.

8. van der Wal J. The architecture of the connective tissue in the musculoskeletal system-an often overlooked functional parameter as to proprioception in the locomotor apparatus. Int J Ther Massage Bodywork. 2009;2(4):9-23.

9. Bai Y, Yuan L, Soh KS, et al. Possible applications for fascial anatomy and fasciaology in traditional Chinese medicine. J Acupunct Meridian Stud. 2010;3(2):125-132.

10. Buckley CD, Pilling D, Lord JM, Akbar AN, Scheel-Toellner D, Salmon M. Fibroblasts regulate the switch from acute resolving to chronic persistent inflammation. Trends Immunol. 2001;22(4):199-204.

11. Guimberteau JC, Delage JP, McGrouther DA, Wong JK. The microvacuolar system: how connective tissue sliding works. J Hand Surg Eur Vol. 2010;35(8):614-622.

12. Stecco C, Stern R, Porzionato A, et al. Hyaluronan within fascia in the etiology of myofascial pain. Surg Radiol Anat. 2011;33(10):891-896.

13. Abu-Hijleh MF, Roshier AL, Al-Shboul Q, Dharap AS, Harris PF. The membranous layer of superficial fascia: evidence for its widespread distribution in the body. Surg Radiol Anat. 2006;28(6):606-619.

14. Langevin HM, Cornbrooks CJ, Taatjes DJ. Fibroblasts form a body-wide cellular network. Histochem Cell Biol. 2004;122(1):7-15.

15. Langevin HM, Bouffard NA, Fox JR, et al. Fibroblast cytoskeletal remodeling contributes to connective tissue tension. J Cell Physiol. 2011;226(5):1166-1175.

16. Pollack GH. The Fourth Phase of Water: a role in fascia? J Bodyw Mov Ther. 2013;17(4):510-511.
17. Li HY, Chen M, Yang JF, et al. Fluid flow along venous adventitia in rabbits: is it a potential drainage system complementary to vascular circulations? PLoS One. 2012;7(7):e41395.

18. Lee BC, Yoon JW, Park SH, Yoon SZ. Toward a theory of the primo vascular system: a hypothetical circulatory system at the subcellular level. Evid Based Complement Alternat Med. 2013;2013: 961957.

19. Li HY, Yang JF, Chen M, et al. Visualized regional hypodermic migration channels of interstitial fluid in human beings: are these ancient meridians? J Altern Complement Med. 2008;14(6):621-628.

20. Park ES, Kim HY, Youn DH. The primo vascular structures alongside nervous system: its discovery and functional limitation. Evid Based Complement Alternat Med. 2013;2013:538350.

21. Soh KS. Bonghan circulatory system as an extension of acupuncture meridians. J Acupunct Meridian Stud. 2009;2(2):93-106.

22. Stecco C, Tiengo C, Stecco A, et al. Fascia redefined: anatomical features and technical relevance in fascial flap surgery. Surg Radiol Anat. 2013;35(5):369-376.

23. Lee S, Joo KB, Song SY. Accurate definition of superficial and deep fascia. Radiology. 2011;261(3):994; author reply 994-995; author reply 995.

24. Turrina A, Martínez-González MA, Stecco C. The muscular force transmission system: role of the intramuscular connective tissue. J Bodyw Mov Ther. 2013;17(1):95-102.

25. Purslow PP. Muscle fascia and force transmission. J Bodyw Mov Ther. 2010;14(4):411-417.

26. Stecco C, Gagey O, Belloni A, et al. Anatomy of the deep fascia of the upper limb. Second part: study of innervation. Morphologie. 2007;91(292):38-43.

27. Authier FJ, Chariot P, Gherardi RK. Skeletal muscle involvement in human immunodeficiency virus (HIV)-infected patients in the era of highly active antiretroviral therapy (HAART). Muscle Nerve. 2005;32(3):247-260.

28. McLoughlin DM, Spargo E, Wassif WS, et al. Structural and functional changes in skeletal muscle in anorexia nervosa. Acta Neuropathol. 1998;95(6):632-640.

29. Olsson AH, Rönn T, Elgzyri T, et al. The expression of myosin heavy chain (MHC) genes in human skeletal muscle is related to metabolic characteristics involved in the pathogenesis of type 2 diabetes. $\mathrm{Mol}$ Genet Metab. 2011;103(3):275-281.

30. Urbano-Márquez A, Fernández-Solà J. Effects of alcohol on skeletal and cardiac muscle. Muscle Nerve. 2004 30(6):689-707.

31. Diffee GM, Kalfas K, Al-Majid S, McCarthy DO. Altered expression of skeletal muscle myosin isoforms in cancer cachexia. Am J Physiol Cell Physiol. 2002;283(5):C1376-C1382.

32. Sakkas GK, Ball D, Mercer TH, Sargeant AJ, Tolfrey K, Naish PF. Atrophy of non-locomotor muscle in patients with end-stage renal failure. Nephrol Dial Transplant. 2003;18(10):2074-2081.

33. Couillard A, Prefaut C. From muscle disuse to myopathy in COPD: potential contribution of oxidative stress. Eur Respir J. 2005;26(4):703-719.

34. Vescovo G, Serafini F, Facchin L, et al. Specific changes in skeletal muscle myosin heavy chain composition in cardiac failure: differences compared with disuse atrophy as assessed on microbiopsies by high resolution electrophoresis. Heart. 1996;76(4):337-343.

35. Toffola ED, Sparpaglione D, Pistorio A, Buonocore M. Myoelectric manifestations of muscle changes in stroke patients. Arch Phys Med Rehabil. 2001;82(5):661-665.

36. Ciciliot S, Rossi AC, Dyar KA, Blaauw B, Schiaffino S. Muscle type and fiber type specificity in muscle wasting. Int J Biochem Cell Biol. 2013;45(10):2191-2199.

37. Bernardi P, Bonaldo P. Mitochondrial dysfunction and defective autophagy in the pathogenesis of collagen VI muscular dystrophies. Cold Spring Harb Perspect Biol. 2013;5(5):a011387.

38. Giacomelli IL, Steidle LJ, Moreira FF, Meyer IV, Souza RG, Pincelli MP. Hospitalized patients with COPD: analysis of prior treatment. J Bras Pneumol. 2014;40(3):229-237. 
39. Stendardi L, Grazzini M, Gigliotti F, Lotti P, Scano G. Dyspnea and leg effort during exercise. Respir Med. 2005;99(8):933-942.

40. Savage PA, Shaw AO, Miller MS, et al. Effect of resistance training on physical disability in chronic heart failure. Med Sci Sports Exerc. 2011;43(8):1379-1386.

41. Erbs S, Höllriegel R, Linke A, et al. Exercise training in patients with advanced chronic heart failure (NYHA IIIb) promotes restoration of peripheral vasomotor function, induction of endogenous regeneration, and improvement of left ventricular function. Circ Heart Fail. 2010;3(4):486-494.

42. Mastaglia FL. The relationship between muscle pain and fatigue. Neuromuscul Disord. 2012;22 Suppl 3:S178-S180.

43. Clark AK, Old EA, Malcangio M. Neuropathic pain and cytokines: current perspectives. J Pain Res. 2013;6:803-814.

44. Gan WQ, Man SF, Senthilselvan A, Sin DD. Association between chronic obstructive pulmonary disease and systemic inflammation: a systematic review and a meta-analysis. Thorax. 2004;59(7): 574-580.

45. Dixon DL, Griggs KM, Bersten AD, De Pasquale CG. Systemic inflammation and cell activation reflects morbidity in chronic heart failure. Cytokine. 2011;56(3):593-599.

46. Duncan BB, Schmidt MI, Pankow JS, et al; Atherosclerosis Risk in Communities Study. Low-grade systemic inflammation and the development of type 2 diabetes: the atherosclerosis risk in communities study. Diabetes. 2003;52(7):1799-1805.

47. Liptan GL. Fascia: A missing link in our understanding of the pathology of fibromyalgia. J Bodyw Mov Ther. 2010;14(1):3-12.

48. McPartland JM. Expression of the endocannabinoid system in fibroblasts and myofascial tissues. J Bodyw Mov Ther. 2008;12(2):169-182.

49. Hicks MR, Cao TV, Campbell DH, Standley PR. Mechanical strain applied to human fibroblasts differentially regulates skeletal myoblast differentiation. J Appl Physiol (1985). 2012;113(3):465-472.

50. Rowe PC, Fontaine KR, Violand RL. Neuromuscular strain as a contributor to cognitive and other symptoms in chronic fatigue syndrome: hypothesis and conceptual model. Front Physiol. 2013;4:115.

51. Stecco A, Meneghini A, Stern R, Stecco C, Imamura M. Ultrasonography in myofascial neck pain: randomized clinical trial for diagnosis and follow-up. Surg Radiol Anat. 2014;36(3):243-253.

52. Langevin HM, Nedergaard M, Howe AK. Cellular control of connective tissue matrix tension. J Cell Biochem. 2013;114(8):1714-1719.

53. Eagan TS, Meltzer KR, Standley PR. Importance of strain direction in regulating human fibroblast proliferation and cytokine secretion: a useful in vitro model for soft tissue injury and manual medicine treatments. J Manipulative Physiol Ther. 2007;30(8):584-592.

54. Cao TV, Hicks MR, Campbell D, Standley PR. Dosed myofascial release in three-dimensional bioengineered tendons: effects on human fibroblast hyperplasia, hypertrophy, and cytokine secretion. J Manipulative Physiol Ther. 2013;36(8):513-521.

55. Deising S, Weinkauf B, Blunk J, Obreja O, Schmelz M, Rukwied R. NGF-evoked sensitization of muscle fascia nociceptors in humans. Pain. 2012;153(8):1673-1679.

56. Shah JP, Gilliams EA. Uncovering the biochemical milieu of myofascial trigger points using in vivo microdialysis: an application of muscle pain concepts to myofascial pain syndrome. J Bodyw Mov Ther. 2008;12(4):371-384.

57. Fernández-de-las-Peñas C, Dommerholt J. Myofascial trigger points: peripheral or central phenomenon? Curr Rheumatol Rep. 2014;16(1):395

58. Muscolino JE. Abdominal wall trigger point case study. J Bodyw Mov Ther. 2013;17(2):151-156.

59. Langevin HM. Connective tissue: a body-wide signaling network? Med Hypotheses. 2006;66(6):1074-1077.

60. Mori G, D'Amelio P, Faccio R, Brunetti G. The Interplay between the bone and the immune system. Clin Dev Immunol. 2013;2013:720504.

61. Nakashima T, Takayanagi H. Osteoimmunology: crosstalk between the immune and bone systems. J Clin Immunol. 2009;29(5): $555-567$.
62. Vi L, Feng L, Zhu RD, et al. Periostin differentially induces proliferation, contraction and apoptosis of primary Dupuytren's disease and adjacent palmar fascia cells. Exp Cell Res. 2009;315(20):3574-3586.

63. Norris RA, Damon B, Mironov V, et al. Periostin regulates collagen fibrillogenesis and the biomechanical properties of connective tissues. J Cell Biochem. 2007;101(3):695-711.

64. Kotarinos R. Myofascial pelvic pain. Curr Pain Headache Rep. 2012;16(5):433-438.

65. Bordoni B, Zanier E. Anatomic connections of the diaphragm: influence of respiration on the body system. J Multidiscip Healthc. 2013;6:281-291.

66. Langevin HM, Fox JR, Koptiuch C, et al. Reduced thoracolumbar fascia shear strain in human chronic low back pain. BMC Musculoskelet Disord. 2011;12:203.

67. Willard FH, Vleeming A, Schuenke MD, Danneels L, Schleip R. The thoracolumbar fascia: anatomy, function and clinical considerations. J Anat. 2012;221(6):507-536.

68. Tesarz J, Hoheisel U, Wiedenhöfer B, Mense S. Sensory innervation of the thoracolumbar fascia in rats and humans. Neuroscience. 2011;194:302-308.

69. Hoheisel U, Taguchi T, Treede RD, Mense S. Nociceptive input from the rat thoracolumbar fascia to lumbar dorsal horn neurones. Eur $J$ Pain. 2011;15(8):810-815.

70. Schilder A, Hoheisel U, Magerl W, Benrath J, Klein T, Treede RD. Sensory findings after stimulation of the thoracolumbar fascia with hypertonic saline suggest its contribution to low back pain. Pain. 2014;155(2):222-231.

71. Carvalhais VO, Ocarino Jde M, Araújo VL, Souza TR, Silva PL, Fonseca ST. Myofascial force transmission between the latissimus dorsi and gluteus maximus muscles: an in vivo experiment. $J$ Biomech. 2013;46(5):1003-1007.

72. Barker PJ, Hapuarachchi KS, Ross JA, Sambaiew E, Ranger TA, Briggs CA. Anatomy and biomechanics of gluteus maximus and the thoracolumbar fascia at the sacroiliac joint. Clin Anat. 2014;27(2): 234-240.

73. Huang BK, Campos JC, Michael Peschka PG, et al. Injury of the gluteal aponeurotic fascia and proximal iliotibial band: anatomy, pathologic conditions, and MR imaging. Radiographics. 2013;33(5): 1437-1452.

74. Stecco C, Pavan P, Pachera P, De Caro R, Natali A. Investigation of the mechanical properties of the human crural fascia and their possible clinical implications. Surg Radiol Anat. 2014;36(1):25-32.

75. Pedrelli A, Stecco C, Day JA. Treating patellar tendinopathy with Fascial Manipulation. J Bodyw Mov Ther. 2009;13(1):73-80.

76. Stecco C, Corradin M, Macchi V, et al. Plantar fascia anatomy and its relationship with Achilles tendon and paratenon. $J$ Anat. 2013;223(6):665-676.

77. Stecco A, Antonio S, Gilliar W, et al. The anatomical and functional relation between gluteus maximus and fascia lata. J Bodyw Mov Ther. 2013;17(4):512-517.

78. Li S, Kukulka CG, Rogers MW, Brunt D, Bishop M. Sural nerve evoked responses in human hip and ankle muscles while standing. Neurosci Lett. 2004;364(2):59-62.

79. Tozzi P, Bongiorno D, Vitturini C. Fascial release effects on patients with non-specific cervical or lumbar pain. J Bodyw Mov Ther. 2011;15(4):405-416.

80. El Hage Y, Politti F, Herpich CM, et al. Effect of facial massage on static balance in individuals with temporomandibular disorder - a pilot study. Int J Ther Massage Bodywork. 2013;6(4):6-11.

81. Ohlendorf D, Riegel M, Lin Chung T, Kopp S. The significance of lower jaw position in relation to postural stability. Comparison of a premanufactured occlusal splint with the Dental Power Splint. Minerva Stomatol. 2013;62(11-12):409-417.

82. Sforza C, Tartaglia GM, Solimene U, Morgun V, Kaspranskiy RR, Ferrario VF. Occlusion, sternocleidomastoid muscle activity, and body sway: a pilot study in male astronauts. Cranio. 2006;24(1): 43-49. 
83. Otadi K, Hadian MR, Talebian S, Shadmehr A, Emamdoost S, Shahriar G. The effect of myofascial neck pain on postural control: visual deprivation. J Back Musculoskelet Rehabil. 2013;26(4):375-380.

84. Guidera AK, Dawes PJ, Fong A, Stringer MD. Head and neck fascia and compartments: No space for spaces. Head Neck. 2014;36(7): 1058-1068.

85. Warshafsky D, Goldenberg D, Kanekar SG. Imaging anatomy of deep neck spaces. Otolaryngol Clin North Am. 2012;45(6):1203-1221.

86. Kelders WP, Kleinrensink GJ, van der Geest JN, Feenstra L, de Zeeuw CI, Frens MA. Compensatory increase of the cervico-ocular reflex with age in healthy humans. J Physiol. 2003;553(Pt 1):311-317.

87. Bexander CS, Hodges PW. Cervico-ocular coordination during neck rotation is distorted in people with whiplash-associated disorders. Exp Brain Res. 2012;217(1):67-77.

88. Kushima H, Matsuo K, Yuzuriha S, Kitazawa T, Moriizumi T. The occipitofrontalis muscle is composed of two physiologically and anatomically different muscles separately affecting the positions of the eyebrow and hairline. Br J Plast Surg. 2005;58(5):681-687.

89. Matsuo K, Osada Y, Ban R. Electrical stimulation to the trigeminal proprioceptive fibres that innervate the mechanoreceptors in Müller's muscle induces involuntary reflex contraction of the frontalis muscles. J Plast Surg Hand Surg. 2013;47(1):14-20.

90. Matsuo K, Ban R. Surgical desensitisation of the mechanoreceptors in Müller's muscle relieves chronic tension-type headache caused by tonic reflexive contraction of the occipitofrontalis muscle in patients with aponeurotic blepharoptosis. J Plast Surg Hand Surg. 2013;47(1):21-29.

91. Standerwick RG, Roberts WE. The aponeurotic tension model of craniofacial growth in man. Open Dent J. 2009;3:100-113.

92. Kakizaki H, Takahashi Y, Nakano T, et al. Anatomy of Tenons capsule. Clin Experiment Ophthalmol. 2012 40(6):611-616.

93. Kakizaki H, Takahashi Y, Nakano T, et al. Müller's muscle: a component of the peribulbar smooth muscle network. Ophthalmology. 2010;117(11):2229-2232.

94. Tsamis A, Krawiec JT, Vorp DA. Elastin and collagen fibre microstructure of the human aorta in ageing and disease: a review. $J$ R Soc Interface. 2013;10(83):20121004.

95. Burlew BS, Weber KT. Connective tissue and the heart. Functional significance and regulatory mechanisms. Cardiol Clin. 2000;18(3):435-442.

96. Rabinowitz JG, Cohen BA, Mendleson DS. Symposium on Nonpulmonary Aspects in Chest Radiology. The pulmonary ligament. Radiol Clin North Am. 1984;22(3):659-672.

97. Nappi G, Tritto FP, Falco A, Longobardi F, Cotrufo M. New surgical technique for harvesting the internal mammary artery. Tex Heart Inst J. 1994;21(2):134-137.

98. Kodo K, Yamagishi H. A decade of advances in the molecular embryology and genetics underlying congenital heart defects. Circ J. 2011;75(10):2296-2304.
99. Santoro MM, Pesce G, Stainier DY. Characterization of vascular mural cells during zebrafish development. Mech Dev. 2009;126(8-9): 638-649.

100. Whedon JM, Glassey D. Cerebrospinal fluid stasis and its clinical significance. Altern Ther Health Med. 2009;15(3):54-60.

101. Gard G. An investigation into the regulation of intra-cranial pressure and its influence upon the surrounding cranial bones. J Bodyw Mov Ther. 2009;13(3):246-254.

102. Skedung L, Arvidsson M, Chung JY, Stafford CM, Berglund B, Rutland MW. Feeling small: exploring the tactile perception limits. Sci Rep. 2013;3:2617.

103. Bulat M, Klarica M. Recent insights into a new hydrodynamics of the cerebrospinal fluid. Brain Res Rev. 2011;65(2):99-112.

104. Gay F. Bacterial toxins and multiple sclerosis. J Neurol Sci. 2007; 262(1-2):105-112.

105. Johnston M, Zakharov A, Papaiconomou C, Salmasi G, Armstrong D. Evidence of connections between cerebrospinal fluid and nasal lymphatic vessels in humans, non-human primates and other mammalian species. Cerebrospinal Fluid Res. 2004;1(1):2.

106. Pan WR, le Roux CM, Levy SM, Briggs CA. The morphology of the human lymphatic vessels in the head and neck. Clin Anat. 2010;23(6):654-661.

107. Sakka L, Coll G, Chazal J. Anatomy and physiology of cerebrospinal fluid. Eur Ann Otorhinolaryngol Head Neck Dis. 2011;128(6) 309-316.

108. Zhong L, Gao Y, Xia H, Li X, Wei S. Percutaneous coronary intervention delays pacemaker implantation in coronary artery disease patients with established bradyarrhythmias. Exp Clin Cardiol. 2013;18(1):17-21.

109. Health Quality Ontario. Implantable cardioverter defibrillators. Prophylactic use: an evidence-based analysis. Ont Health Technol Assess Ser. 2005;5(14):1-74.

110. Giamberti A, Chessa M, Abella R, et al. Surgical treatment of arrhythmias in adults with congenital heart defects. Int J Cardiol. 2008;129(1):37-41.

111. Gervasio A, Mujahed I, Biasio A, Alessi S. Ultrasound anatomy of the neck: The infrahyoid region. J Ultrasound. 2010;13(3):85-89.

112. Miyake N, Takeuchi H, Cho BH, Murakami G, Fujimiya M, Kitano H. Fetal anatomy of the lower cervical and upper thoracic fasciae with special reference to the prevertebral fascial structures including the suprapleural membrane. Clin Anat. 2011;24(5):607-618.

113. Anastasi et al. AA VV, Anatomia dell'uomo, 4th ed, Edi.ermes, Milano [Human Anatomy]. Available from: http://www.eenet.it. Accessed September 9, 2014
Journal of Multidisciplinary Healthcare

\section{Publish your work in this journal}

The Journal of Multidisciplinary Healthcare is an international, peerreviewed open-access journal that aims to represent and publish research in healthcare areas delivered by practitioners of different disciplines. This includes studies and reviews conducted by multidisciplinary teams as well as research which evaluates the results or conduct of such teams or

\section{Dovepress}

healthcare processes in general. The journal covers a wide range of areas and welcomes submission from practitioners at all levels, from all over the world. The manuscript management system is completely online and includes a very quick and fair peer-review system. Visit http://www.dovepress.com/testimonials.php to read real quotes from published authors. 